\title{
A Late Acheulean Culture on the Chinese Loess Plateau: The Techno-economic Behavior of the Dingcun lithic industry
}

\author{
Shi-Xia Yang ${ }^{a b} \quad$ Ya-MeiHou Jacques Pelegrin $^{c}$ \\ a State Key Laboratory of Lithospheric Evolution, Institute of Geology and \\ Geophysics, Chinese Academy of Sciences, Beijing 100029, China; \\ ${ }^{\mathrm{b}}$ Institute of Vertebrate Paleontology and Paleoanthropology, Chinese Academy of \\ Sciences, Beijing 100044, China; \\ 'MAE, UMR 7055 "Préhistoire et Technologie", CNRS et U. Paris Ouest Nanterre, \\ Nanterre cedex 92023, France
}

\section{Abstract}

The Chinese Loess Plateau is the largest loess area in the world, andcovers $\sim 400,000$ $\mathrm{km}^{2}$, with a loess-palaeosol sequence that is comparable with Marine Isotope Stages (MIS) as a Quaternary terrestrial timescale of climatostratigraphy and chronology. The Dingcun lithic industry was recovered in 1954 inthe Loess Plateau, and has been known for its Large Flake Acheulean tools. Technological analysisbased onthe concept of chaîneopératoirewas applied in this paper to update our knowledge of the techno-economic behaviours at thissite and in the Loess Plateau area. The results show that there are two chaîneopératoires: 1) one focused on the production of large flake blanks (façonnage) for making Large Cutting Tools (LCTs); and 2) a small to medium débitage to obtain flakes for light duty tools.Experiments were applied to check the knapping technique. The results confirmed the probability that hard hammers were used to produce large flakes on hornfels blanks, and soft-hammer techniques were not used. When compared with the Acheulian LCTs of other sites in China, Dingcun is different from the Acheulian culture of south China (Danjiangkou Reservoir Region [DRR] and the Bose Basin), and more similar to the Luonan Acheulian industry. Therefore, it seems that a Large Flake Acheulean was developed the Loess Plateau area in the Late Middle Pleistocene. 
Keywords: Dingcun lithic industry, Late Acheulean, Loess Plateau area, Chaîneopératoires, Knapping experiment

\section{Introduction}

Despite several years of detailed research on Chinese Acheulean assemblages, the long-standing debate about the reality of the Movius Line still continues(Movius, 1944, 1948; Huang,1987;Hou et al.,2000; Kuman et al., 2014; Li et al., 2014; Yang et al., 2014).Recently, the geological and archaeological materials which served as the basis forthe Movius Line were checked, and shown to be unreliable (Dennell, 2014a, b).Therefore, it is widely accepted that the Acheulean culture was anOld World phenomenon that persisted for a long period in early prehistory (Goren and Sharon, 2006; Derevianko, 2008; Doronichev and Golovanova, 2010; Lepre et al., 2011; Brumm and Moore, 2012; Bar-Yosef and Wang, 2012; Kuman et al., 2014). After burying the Movius line, we shouldhighlight the need for greater reliance on technological analysis and raw material evaluation for better comparisons between the Acheulean assemblagesfrom Chinaand other regions.

Within the three areas containing the Acheulean or Acheulean like culture in China, the most northerly one is the Loess Plateau area, where the site complexes of Dingcun(Ting-Ts'un) and the Luonan basin(Shaanxi Province) are the representative ones (Fig. 1a). Since discovered in 1954, the Dingcun site has been known for its heavy-duty tools, especially the trihedral picks, which are regarded as representative of a Lower Paleolithic tradition in North China (Jia et al., 1972). Most studies of the Dingcun industry involve typological assignation of the large tools as Acheulean and regional comparisons with other Acheulean sites (Jia, 1955, 1956; in Pei, 1965; Freeman, 1977; Aigner, 1978; Huang, 1987; Liu, 1988; Lin, 1992; Wang, 2006; Yang et al., 2014), while analysis of the chaîneopératoire and the knapping technique were seldom discussed.

In this paper, we have restudied theDingcun lithic industry, including its raw material sourcingand chaîneopératoire, and conducted knapping experiments (see Yang et al.,2014; Yang et al.,2015).We also take other Chinese Acheulean sites into 
account to establish the characteristics of the Acheulean culture in Loess Plateau.

\section{Dingcun site and its lithic assemblage}

The Paleolithic sites at Dingcun lie in the rift zone of the Fenhe Graben in the eastern Chinese Loess Plateau (Fig.1a). During 1954-1955, 13 localities were found and excavated, and noted as 54:90-54:102. All these localities lie on the third Terrace of Fenhe River (Fig. 1b). In two years of field work, 2005 artifacts were recovered, of which 225 were from the surface, and the others were in situ (Pei et al., 1958). Among the 13 localities, Localities 90, 97, 98, 99, 100, and 102 are located within a few hundred meters (Fig. 1c) of each other. More than $80 \%$ of the artifacts were from these localities, and therefore this cluster can be regarded as the central part of the site. Although the first formal report and later study briefly concluded that all the localities

were in the same strata and had similar taphonomichistories (Pei et al., 1958; Wang, 2002), there are doubts aboutthese conclusions (Zhang, 1993, 1994).

One doubt is that the artifacts from different localities are not of the same size range (Zhang, 1993, 1994). Therefore statistical analysis on the maximal length of the artifacts from different localities has been done (Fig. 2). From the graph, we find that the artifacts from different localities are similar in length, and the ones from the collection are larger.We also evaluated the taphonomic situation of the artifacts (Fig. 3 ), and the results showed that most of the artifacts are slightly abraded or fresh. The 40 artifacts which are heavily abradedare not included in this study.Regarding the depositional processes of the artifacts, we agreed with some early studies(Pei et al., 1958; Wang, 2002) that the artifacts may have been transported by waterovera short distance or immersed in the water for some time, for the artifacts were in the terrace close to the river. The Dingcun sites are placed on a relative scale of the influence of moving water on the assemblages.

Although Pei (1958) stated that Dingcun was Late Pleistocene in age, the cultural layer is below the first paleosol (S1) which is dated to 73-128 ka (Kukla and An, 1989; Ding et al., 1991, 1994; Wu and Liu, 2002), and the U-series dating results of this layer is $160-210 \mathrm{ka}$ (Chen et al., 1984). Therefore, the Dingcun assemblageis datedin 
recent work to the Late Middle Pleistocene (Yang et al., 2014). Locality 54:100 $\left(35^{\circ} 49^{\prime} \mathrm{N}, 111^{\circ} 25^{\prime} \mathrm{E}\right)$, where three teeth of Homo $s p$. were found, is considered as representative of the others. The archaeological layer is about $4 \mathrm{~m}$ thick, and is the upper part of a $20 \mathrm{~m}$ thick fluvial deposit. Above the cultural layer is a $10 \mathrm{~m}$ thick aeolian deposit that includes the first paleosol (S1) of the Upper Pleistocene (Malan loess) and the Holocene paleosol (S0).

\section{Materials and method}

\subsection{Chaîneopératoire study}

Following the chaîneopératoire approach, we regard the production of stone artifacts as a dynamic process, from the acquisition of raw material to the discard of used tools. It thus aims at re-establishing the whole process of the lifetime of the stone tools. In this process, there are four main parts: raw material acquisition, production, utilization, and discard. Some factors make it difficult to determine the utilization and discard of the stone artifacts, especially in Lower Paleolithic sites (Boëda,1990; Julien,1992; Roche and Texier, 1995,1996). Because of the taphonomic situation of the artifacts in Dingcun, it is impossible to study the context of their utilization and discard. Therefore, in this paper, we focus on the acquisition of raw material and tool production.

The raw materials are dominated by hornfels (94.6\%), but chert and quartz are also present. The hornfels used in Dingcun lithic industryis from outcrops aroundDagudui Mountain, which is $7 \mathrm{~km}$ from the Dingcun site (Pei et al.,1958;Wang et al.,1987; Yang et al., 2015). The raw material acquisition of Dingcunis similarto that at other Acheulean sites: raw materials were probably first tested and flaked at the quarry site, and then brought back to the site as prepared cores or large flake-blanks (Texier and Roche, 1995; Inizan et al.,1999).Therefore the large cores for making blanks for large-flake tools such as handaxes or cleaver are almost absent in the site.

Between 2013 and 2015, the artifacts found in situ were analyzed.A descriptive rather than a quantitative approach is adopted to assess the range of variation and to characterize the modes of lithic production. A classification of the cores, which are 
particularly informative inassessments of knapping methods and techniques, was performed using the identification of the number of flaking surfaces, the direction of flaking and the preparation of the platform. The analysis of flakes takes into account the type of butt, thenumber and direction of negative scars on the dorsal face, and the presence of lips. The analysis of large cutting tools (LCT) considers the blank types, the presence/location/extension of façonnage and retouch, the presence of standardized shapes and sizes. In addition, the analysis of light duty tools also considers the blank types, the retouch methods and the retouch locations.

\subsection{Knapping experiment}

Knapping experiments are a vital way to test raw materials and access flaking techniques(Newcomer,1971; Driscolland and García-Rojas,2014; Terradillos-Bernal et al.,2014).Here, knapping experiments can show what kind of characteristics hornfels may have had to make it the principal raw material. The knapping technique in Dingcun industry is also a long-standing question, as the large wide flakes were supposedly produced by the block-on-block method (Pei et al., 1958; Li, 1996a, 1996b), and this claim has been supported in several subsequent studies (Liu, 1988; Li, 1992; Wang, 2001). Based on technological analysis of the Dingcunartifacts, we deducedthat the hard hammer percussion was in fact the main knapping technique.However, we need to use experiments to demonstrate that possibility, and also establish whether the soft organic hammer percussionwas used to produce large flakes on hornfels.

The hornfels used in the experiment were mainly blocks from the hornfels outcrops around the Daguidui Mountain, but a few were collected from gullies near Dingcun.Two organic hammers were prepared: one was a 2000gm hard box wood hammer, the other one was an antler. Several 2000-500gm hard hammers were also prepared. The participant, who mainly controlled the experiments, is an accomplished knapper with around 30 years of knapping experience.

During the knapping of each nodule, the majority of debitage was collected periodically and bagged, and after the knapping of each nodule, all the cores and 
remaining debitage (mainly fragments and $<20$ mmdebitage) were labeled and bagged. After testing the raw materials, the hard hammer and organic hammer were used to produce flakes respectively.

\section{Results}

\subsection{Two chaîneopératoires}

Two main chaînesopératoirescoexisted in the Dingcun industry:one was devoted to the production of large flakes that could be turned into LCTs and the other focused on the débitage of small to medium-sized flakes which could be used to produce light-duty tools. We describe the two chaînesopératoires as follows.

\section{$\underline{\text { 4.1.1 Production of large flakes }}$}

As mentioned in former studies, the large cores for making blanks for large-flake tools such as handaxes or cleavers are almost absent in the site (Yang et al., 2014, 2015).This is a common situation, as rocks large, heavy, and angular enough to produce large flakes weredebitaged in the outcrops (Texier and Roche, 1995). Therefore in this study, we inferred the production of large flakes by analyzing them and the large flake tools. In the assemblage, there are 48 flakes with a maximal length or width $>100 \mathrm{~mm}(8.3 \%$ of all the flakes), but nocore with negative scars with a maximal length or width $>100 \mathrm{~mm}$. When analyzing the techniques of producing the large flakes, we consider the LCT tool-blanks. The large flakesare mainly with two kinds of butts: the plain and the dihedral. Most have prominent bulbs, bulb scars, and the waves (or ripple) at the distal parts. In the former studies, several giant core methods, such as the bifacial,sliced slab, opening flake methods, the Victoria West, Tabelbala-Tachenghit and Chirki cleaver core were identified (Sharon, 2007).

From observing the large flakes from Dingcun, at least four kinds of giant core methods were used. The bifacial method is very common in large flake production(Madsen and Goren-Inbar, 2004; Sharon, 2007). In this method, after detaching a primary opening flake, the knapper worked alternately along the core's periphery, removing a series of flakes from both faces of the core, while using the scar of the previously removed flake as the striking platform (Sharon, 2007). In this 
situation, the large flakes are always with plain butts or a pseudo-dihedral butts(Fig.4-1/2, N=38, 79\%). The sliced slab method is related to the morphology of raw materials, and always used on flat slabs of raw material. As the hornfels are derived from shale or sandy shale, it is easy to find the blocks in flat slabs.Another method may be related to the large flake production in Dingcun is the opening flake method, as it is effective to produce thin flakes with nature dorsal face (the blank of pick, such as Fig.5-b, $\mathrm{N}=6,13 \%$ ).

The most important one is theChirki cleaver core. The Chirki cleaver core was first named and introduced byCorvinus(1983) in an Indian Acheulean context.A few flakes were at one side and a 'base' was then prepared, which determined the future dorsal face of the cleaver flake(Fig.6, $N=4,8 \%$ ).Here, we show an example from Dingcunindustry.By reading the scars of the cleaver(P0139),we can replay the process of the production of this flake blank (Fig.5-a).

\subsubsection{Façonnage of the large cutting tools}

The façonnage of the large cutting tools of Dingcun can be divided into two groups. The first group includes the handaxe/cleaver/pick $(\mathrm{N}=39,59 \%$ of the large cutting tools, details inTable 1). These tools get the morphological standardizationin the façonnage process, and the final retouches are taken based on the specific forms.As examples, in Figs. 5-b/c, the pick and biface are with symmetrical. The cleaver is on a Chirki cleaver flake, and retouch is helping to get an equilibrium butt (Fig.5a).The tools in the second group lack morphological standardization: retouch was not undertaken to obtain a specific formsuch as massive scrapers and denticulates but only to modify the edge ( $N=27,41 \%$, see Table 1$)$. These massive edge-tools were not in a standard form. In Fig.5d, two edgeswere retouched, while another example, specimen P1980(Fig.5e) lostmuch of its volume, and hada very irregular morphology. Neither example shows an intentionofobtaining astandardized morphology. 


\subsection{Small to medium débitageand light duty tools}

A total of 91 cores, 531 flakes, 122 flake fragments,and 163 light duty tools are documented in the second chaîneopératoire. Here, flakes in thesmall-medium débitage were used to produce light duty tools. The raw materials are dominated by hornfels, while the chert and quartz were also used.

Most of the cores in the Dingcun assemblage have dimensions of $\sim 50 \mathrm{~mm}$, and only few $(\mathrm{N}=14 ; 13 \%)$ exceed $100 \mathrm{~mm}$. Based on their platforms and morphology, we classified the cores into five types, named as A-E (Fig. 7). Type A and Type E are the commonest ones. The Type A $(\mathrm{N}=25 ; 26.6 \%)$ is a simple way to exploit the core, and a few $(\mathrm{N}=8)$ had retouched platforms. The Type $\mathrm{E}(\mathrm{N}=27 ; 29.3 \%$, Fig. 12)coreis the commonest. This method is very productive and used the former flake scar to produce the next flake (Mourre, 2003; Terradas, 2003; Soressi, 2005). Some have a very discoid outline, when the alternating surface is in the middle of the core (Fig. 8-a/b), therefore in several reports it was called a discoid core. It belonged to an enlarged "discoid" core, as it cannot be exactly categorized into the original definition (Boëda, 1995).

Type $\mathrm{B}(\mathrm{N}=11 ; 12 \%)$ is a bipolar exploited core. These cores have two opposite platforms, and only one with a prepared platform.Type $\mathrm{C}(\mathrm{N}=7 ; 7.6 \%)$ has anorthogonal negative scar pattern, as the debitage happened on one face from orthogonal directions. The Type $(\mathrm{N}=21 ; 22.8 \%)$ is a multifacial, multidirectional and irregular core. Core surfaces were alternatively flaked through multidirectional removals without a clear organization of the reduction process.

Most of the flakesin the Dingcun industry are $<10 \mathrm{~cm}$ long or wide (Fig.9), and belong to the small to medium-sizeddébitage (Sharon, 2010; de la Torre, 2011a; Beyene et al., 2013). When checking the length/width ratio, the length of $40 \%$ of flakes exceeded the width. The platform angles are $70 \sim 90^{\circ}$, and cluster on $75 \sim 85^{\circ}$. The butts of the flakes can be divided into four types: plain (67\%), dihedral (10\%), facetted (19\%) and linear $(4 \%)$.

The dorsal face patterns of the flakes are dominated bymultidirectional irregular negative scar patterns $(32 \%)$, while the scars formed a ridge at the dorsal face. The 
other two types constitute a large set and are ones with a natural surface (16\%) and unidirectional negative scar pattern(25\%). The others types are the centripetal negative scar pattern, thecore edge flakes, and the bidirectional negative scar pattern. The broken flakes of Dingcun have a relatively high proportion of "siret" (accidental breakage flakes), which reaches nearly $10 \%$. In a"siret" accident, the flake is snapped into two parts along the percussion axis. This kind of accident is common in hard hammer percussion (Inizan et al., 1999).

In the studied assemblage there are 163 pieces of light duty tools, accounting for $76 \%$ of the tools, including scrapers, notches, denticulates, borers, and some unidentified tools. Most tools $(>92 \%)$ are flake tools, made either on whole or broken flakes. Scrapers form the largest proportion (38.7\%) of light duty tools. The small scrapers studied here have a maximal length and width around $50 \mathrm{~mm}$, and the ones made on chert and quartz are smaller. Most of the scrapers are made on flakes, including some Kombewa flakes (Fig. 10). According to the number of retouched edges and the shape of the edges, they can be classified into four kinds: convergent, single straight, single convex and single concave. Notches account for $21 \%$ of the light duty tools. Most were produced by retouching a notch on one edge of the flake or on both edges. Both Clactonian types and complex notches occur in the Dingcun assemblage (Fig. 10-16, 17); of these, the former is more common ( $79 \%$ of notches). Denticulates are another type of the light duty tools identified at Dingcun. Denticulate sizes are similar to those of the small scrapers. Most of the tools are formed by three to five continuous notches on the edges of the blanks, but some are modified on the transverse distal edges. Most of the retouched edges are slightly abraded, while some fresh ones exhibit an almost serrated edge (Fig.10-9).Compared to the three types of tools mentioned above, borers usually have a smaller maximal length. In most cases, the tool-makers chose to retouch the distal ends for borer modification, but some retouch occurs on the proximal part. The retouch is always in the same direction on the dorsal or on the ventral surface. Most of these artifacts show simple retouch, but there are some examples with multiple retouches (Figs. 10-7). 


\section{Knapping technique}

\subsection{Production of large flakes in the Dingcun industry}

We considered the possibility that the large flakes were produced by hard hammer percussion instead of the block on block method.A hornfels nodule $(45 * 30 * 20 \mathrm{~cm})$ was chosen to finish sequential hard hammer percussion. The knapper successfully produced 64 conchoidalflakes $(>25 \mathrm{~mm})$ and four splinters. We numbered this series of flakes as E-11-1 to E-11-65 (see appendix Table 1 for their dimensions). During the percussion,there were three "siret breaks" (Fig.11). The maximal length and breadth data are shown in Fig.12. It was clear that large flakes which could be used as the blanks of LCTs were successfullyproduced by hard hammer percussion. When checking the length/width ratio, 33\% of flakes had a length exceeding their width, which is close to the $40 \%$ in the archaeological assemblage.

Except for the sequential percussion of one core, several other nodules were tested. In the knapping process, weobtained flakes with double cones or strong waves (Fig13), and all these attributes were deemed to relate to block on block percussion. Here in this experiment, we saw all these in the hard hammer percussion. Therefore the block on block method is not the one we would use to produce large flakes. The existence of the block-on-block method is questioned by many, and it is also regarded as a kind of dangerous method (Bordes and Anderson,1968;Wymer, 1986; Schick and Toth,1994; Ranov, 1995).

According to anthropological work in Australia(R. Gould), the block on block method was defined byCrabtree(1975): the knapper threw the lithic material against boulders and then selected flakes with sharp cutting edges to be used, while others were selected to be modified into functional implements. In the former study, there are no really ancient examples of this kind of method(Ranov, 1995).

\subsection{Is there organic hammer percussion in Dingcun?}

Aiming to check whether there is organic (soft) hammer percussion in Dingcun, we used the stone and organic hammers to produce flakes. First, a $2 \mathrm{~kg}$ box wood hammer was applied, while it did not really work; second, anantler hammer was 
applied, and 24 complete flakes were produced. The flakes produced by the antler hammer were numbered E-3-1 to E-3-24.

After we conducted a comparison among the experimental flakes from the antler and stone hammer, and also the pseudo-organic-hammer flakes from the archaeological assemblage. The platform angles (angle de chasse) of the three groups are compared inFig.14: the angles of the flakes from the archaeological assemblage are more consistent with the ones from the hard hammer percussion, and the values are more variable between $70^{\circ}$ to $85^{\circ}$, while the flakes from the antler hammer are more stable, and are almost around $80^{\circ}$.

The presence of lips is an important criterion to define the organic hammer percussion. In the hard hammer experiment, the frequency of occurrences of the lips is as high as $37 \%$. Therefore, it is reasonable to find flakes with lips in a hard hammer predominant lithic industry. Then we turn to the missing of the impact points, which we also use as a criterion to distinguish the organic hammer from hard stone hammer percussion. The flakes from the hard hammer experiment also have $10 \%$ of the impact points missing. In addition, the morphology of the platforms is observed after the experiment. The platforms from the hard hammer flakes and soft hammer flakes can be distinguished from each other. The soft hammer flakes always have a convex platform, while the hard hammer flakes have plain platforms. Therefore, the experiment result tended to refute the use of soft hammer percussion. The main technique applied on hornfels in Dingcun seems to be the hard hammer percussion.

\section{Discussion}

\subsection{Techno-economic patterns of lithic production at Dingcun}

Through detailed studies on the assemblage of Dingcun lithic industry, the techno-economic behaviors of the habitants of Dingcun culture became clearer. The Large Flake Acheulean tool complex is the main part of the culture, but the development of the small débitage and the light duty tools is another important part of the industry. They are the two chaînesopératoiresthat coexisted in Dingcun industry. Although the limited nature of the early excavation cannot provide us enough 
information onthe collection of all the debris, the formation of the site and the use wears of the tools, the current restudy of the old collection are still appropriate to evaluate the behaviors of the inhabitantsof the Loess Plateau during the Late Middle Pleistocene.

\subsection{Large flake production and the Acheulean tools}

When drawing conclusions on theAcheulean in China, three representative areas were defined. They are the Loess Plateau area along the Yellow River (Dingcun and Luonan), the Middle reach of the Yangtze River (DDR) and the Bose Basin along the upper Pearl River(Huang and Zhang,2010). Compared to the Acheulean or Acheulean-like culture reported in South China, the Acheulean LCTsin Dingcun are mostly made on large flakes (e.g., $82 \%$ of handaxes on flake blanks, $100 \%$ of cleavers on flake blanks). In Luonan the situation is similar(e.g., $65.91 \%$ of handaxes on flake blanks, $100 \%$ of cleavers on flake blanks) (Wang, 2005,2006). In Bose, the situation is different, as more than $43 \%$ of Acheulean heavy duty tools use a pebble as blank (Li et al., 2014). The Large Flake technique is better documented on the Loess Plateau, especially in the Dingcun industry, while the others rely more on river pebbles, and the Acheulean tools directly retouched on a river pebble or on split pebbles. The form of the raw materials of Dingcungives the possibility to develop a large flake production technique system (Yang et al., 2015). In addition, the spheroids are present in both Dingcun(see Table 1) and Luonan(Wang, 2005), while this kind of stone tools rarelyappear in South China.

The results of this study show that four large flake production methods are applied at Dingcun: the bifacial method, opening flake method, the sliced slab method, and the Chirki cleaver core. The bifacial method is defined as a technical process predetermining through previous removals the recurrence of the exploitation. The use of the opening flake method means that the knappers can prefigure the result, and take advantage of the morphology of the opening flake. The application of the sliced slab methodis to cope with the special shape of some raw material. The most important is the Chikri cleaver core method, as it isa more complicatedand predetermined process 
for the production of large flakes. To obtain a cleaver flake with biseau, the knapper used the previous removal scar to produce the end.

Two different strategies are carried out during the process of turning the large flakes into Large Cutting Tools (LCTs). In the first one, specific or systematic morphological traits are required. In the second, the retouch occurred only at the very edges of pieces or changed lots of the blank volume to obtain a sharp use end.

LCT is the predetermined production of the first chaîneopératoire in Dingcun. From our data, we can establish the raw material acquisition process (Yang et al.,2015) and the production process as described earlier in this article.The utilization and discard is hard to deduce, given the limitations of the excavation record and the taphonomic situation.

\subsection{Small débitage and the light duty tools}

Although the LCTs and large flakes are more remarkable in Dingcun, the small débitage and the light duty tools are also major components of the lithic industry. Firstly, they are present in large numbers at Dingcun (see Table 1), and second, they also show advanced production techniques.They formed the other chaîneopératoirewhich was aimed at producing the light duty tools.

Study of the flakes and cores of the small débitage show that the discoid method (bifacial method)was the main core technique applied. The definition of the discoid had been discussed in several studies (Boëda, 1995). A discoid can be a way to produce flakes and also can be oriented toward the production of points(Bourguignon and Turq,2003; Mourre, 2003; Terradas, 2003; Soressi, 2005). The situation in Dingcun, the main purpose to use the discoid method is to produce flakes

efficiently.In some cases, these co-occur with Levallois cores, which are also a kind of prepared cores that keep peripheral convexity during flaking (Boëda, 1995).

The number of light duty tools is increased and new types appear, and some exquisite scrapers indicate the development of a retouch technique.The increasing number of small scrapers and other light duty tools in Late Middle Pleistocene Acheulean assemblages is a phenomenon reported worldwide. As another Late 
Middle Pleistocene Acheulean site complex in North China, the Luonan open air Acheulean sites have several similarities with Dingcun. Not only the African-looking Acheulean tools (Petraglia and Shipton, 2008; Shipton and Petraglia, 2010), but also the light-duty tools accounted for a considerable proportion of the total. The main types include scrapers, points and burins (Wang, 2005). In Africa, Sangoan and Fauresmith sites contain Acheulian and numerous light-duty tools.Several scholars talked about the transition traits of these sites (McBrearty and Brooks, 2000; Clark, 2001a; Tryon and McBrearty, 2002; McBrearty and Tryon, 2006; Van Peer et al., 2003). The Sangoan industry, characterized by heavy duty tools such as picks and core axes, as well as light duty flake tools, has a lot of similarities with Dingcun industry. In both of the two industries, the light duty tools have a rough outline, and most of the retouches are not so regular (Clark, 2001a, 2001b).

\subsection{Knapping technique-a comment on the hard hammer percussion}

The knapping experiment gives us two important clues aboutthe techno-economic behaviors of Dingcun industry. The first one is the possibility of producing large flake by hard hammer percussion instead of by the block-on-block method.The second is to demonstrate that the organic (soft) hammer percussion was not applied. Thus,hard hammer percussion was the main technique in both thedébitage and the façonnage process.

From the experiment, we also learned that the varied attributes, such as the lips, the percussion mark, the platform angles, used to differentiate impacttypes(knapping techniques)sometimes make more confusion than confirmation (Driscoll and

García-Rojas,2014). In our experiment, we used the results of the knapping experiments to compare with the archaeological artifacts. We hope in this way to find which kind of impact type was acutely applied.

\section{Conclusions}

In this restudy, a detailed techno-economic analysis and knapping experiment were applied to define the main characteristics and the techno-economic of 
Dingcunindustry. Although the artifacts are from the excavations of 60 years ago and the taphonomicsituation is not suitable for establishing the utilization and discardprocesses,efforts were made to access the chaîneopératoires of the lithic industry.

1) It is undeniable that the Dingcun industry belonged to the Late Acheulean. The Dingcun industry maintains a developed Acheulian traditional tool kits, but at the same time the light duty tools are important. The number of light duty tools is increased, and some exquisite scrapers indicate the development of retouch technique. The two chaîneopératiores were paralleled in the Dingcun industry, and the residents had a clear knowledge of both

2) The Acheulian LCTs of Dingcun are mainly made on large flakes. It is different from the Acheulian culture of South China (DRR and Bose Basin), while more similar to the Luonan Acheulian industry. Therefore, it seems to us that the Loess Plateau area developed a Large Flake Acheulean in the Late Middle Pleistocene.

3) Two different strategies are carried out during the façonnage of LCTs. The first one, the specific or systematic morphological traits are required. The second one, the retouch occurred only at the very edges of pieces or changed lots of the blank volume to get a sharp end for using.

4) From the recent knapping experiment, the hard hammer percussion is the main knapping technique applied in Dingcun industry. There is no evidence to emphasize the block-on-block method in Dingcun.

In conclusion, the Dingcun industry document a developed Late Acheulean Culture, andcontained a small to medium flakes tool kit as well. The production of the large flakes and the façonnage of LCTs show its technological flexibility. The light duty tool kit is an important supplement for the industry, and also shows the tendency in the Middle Paleolithic.

\section{Acknowledgements}

This research is supported by the CAS Strategic Priority Research Program (No. 
XDA05130203), the National Science Foundation of China (No. 41272033) and the Ministry of Science and Technology of China grant (No. 2014FY110300). We thanks the local museum staffs from Shanxi Province for helping us to finish the knapping experiment.We are also grateful to Yu-Xiu Zhang (University of Chinese Academy of Sciences) for helping to prepare Fig. 1 and Yue Hu for the photograph inFig . 3.

\section{References}

Aigner, J.S.,1978. Important archaeological remain from North China. In: Ikawa-Smith,F. (ed.), Early Paleolithic in south and east Asia. Mouton, Cambridge, pp.70-113.

Bar-Yosef O, Wang Y. Paleolithic archaeology in China. Annual Review of Anthropology, 2012, 41, 319-335.

Beyene, Y., Katoh, S., WoldeGabriel, G., Hart, W.K., Uto, K., Sudo, M., Kondo, M.,Hyodo, M., Renne, P.R., Suwa, G., Asfaw, B., 2013. The characteristics and chronology of the earliest Acheulean at Konso, Ethiopia. Proceedings of the National Academy of Sciences, 110(5), 1584-1591.

Boëda, E., 1995.Levallois: a volumetric construction, methods, a technique. In: H.L Dibble, O Bar-Yosef (Eds.), The Definition and Interpretation of Levallois Technology. Prehistory Press, Madison, pp. 41-68.

Boëda, E., Geneste, J. M., Meignen, L., 1990. Identification de chaînesopératoireslithiques du Paléolithiqueancienetmoyen. Paléo, 2(1), 43-80.

Bordes, F., Anderson, J., 1968.The Old Stone Age.Weidenfeld and Nicolson, London.

Bourguignon, L., Turq, A., 2003. Unechaîneopératoire de débitagediscoïde sur éclat du Moustérien à denticulésaquitain: les exemples de champ Bossuet et deCombe-Grenal c. 14. In: PeresaniM (Ed.), Discoid Lithic Technology. Advances and Implications, British Archaeological Reports International Series 1120. Archeopress, Oxford, UK, pp. 131-152.

Brumm, A., Moore, M.W., 2012. Biface distributions and the Movius line: A Southeast Asian perspective. Australian Archaeology, 74,32-46.

Chen T.M., Yuan S.X., Gao S.J., 1984. The study on Uranium-series dating of fossil 
bones and an absolute age sequence for the main paleolithic sites of North China.ActaAnthropologicaSinica. 3 (3), 259-269 (in Chinese)

Clark, J. D. 2001a. KalamboFalls Prehistoric Site, Volume III: The Earlier Cultures: Middle and Earlier Stone Age. Cambridge University Press, Cambridge.

Clark, J. D. 2001b. Variability in primary and secondary technologies of the Later Acheulian in Africa.In Milliken, S., and Cook, J. (eds.), A very remote period indeed: Papers on the Paleolithic Presented to Derek Roe.Oxford, pp.1-18.

Corvinus, G.,1983. A Survey of the Pravara River System in Western Maharashtra, India:Volume 2 - The Excavation of the Acheulian Site of Chirki-on-Pravara, India. TübingerMonographienzurUrgeschichte.ArchaeologicaVenatoria:

InstitutfürUrgeschichte der UniversitätTübingen, Tübingen.

Corvinus, G., 2004. Homo erectus in East and Southeast Asia, and the questions of the age of the species and its association with stone artifacts, with special attention to handaxelike tools. Quaternary International 117, 141-151.

Crabtree D E.,1975. Comments on lithic technology and experimental archaeology.Lithic technology, 105-114.

de la Torre, I., 2011. The Early Stone Age lithic assemblages of Gadeb (Ethiopia) and the developed Oldowan/early Acheulean in East Africa. Journal of Human Evolution, 60(6), 768-812.

Dennell, R., 2014. Hallam Movius, Helmut de Terra and the Line that never was: Burma, 1938. Living in the Landscape. McDonald Institute for Archaeological Research, pp. 11-35.

Derevianko, A., 2008. The bifacial technique in China. Archaeology Ethnology and Anthropology of Eurasia 33, 2-32.

Ding Z.1., YuZ ,Rutter N. W., et al. 1994. Towards an orbital timescale for Chinese loess deposits. Quaternary Science Reviews 13, 39-70.

Ding Z.L., Yu Z.W., Liu T.S.,1991. Progress in loess research (Part 3): Time scale. Quaternary Sciences 4, 336-348 (in Chinese).

Doronichev, V., Golovanova, L., 2010. Beyond the Acheulean: A view on the Lower Paleolithic occupation of Western Eurasia. Quaternary International 223-224, 
$327-344$

Driscoll K, García-Rojas M., 2014.Their lips are sealed: identifying hard stone, soft stone, and antler hammer direct percussion in Palaeolithic prismatic blade production. Journal of Archaeological Science47, 134-141.

Freeman, L.G., 1977. Paleolithic archaeology and paleoanthropology in China, In:Howells,W.W., Tsuchitani, P.(Eds.), CSCPRC Report No.4. National Academy of Sciences, Washington D.C. pp. 79-113.

Gamble, C., Marshall, G., 2001. The shape of handaxes, the structure of the Acheulian world. In: Milliken, S., and J Cook (Eds.), A Very Remote Period Indeed: Papers on the Palaeolithic Presented to Derek Roe. Oxbow Books, Oxford. Oxbow, Oxford, pp. 19-27.

Hou,Y.M., Potts, R., Yuan, B.Y. et al.,2000. Mid-Pleistocene Acheulean-like stone technology of the Bose Basin, South China. Science, 287, 1622-1626.

Huang W.W., 1987. Bifaces in China.ActaAnthropologicaSinica 6, 61-68 (in Chinese).

Huang, W.W., Zhang, P., 2010. Le contextgeologique des industries lithiques a bifaces en Chine. L'Anthropologie 114, 519-524.

Ikawa-Smith, Fumiko, 1978. Introduction: The Early Paleolithic Tradition of East Asia. In: Ikawa-Smith,F. (ed.), Early Paleolithic in South and East Asia, Mouton, Cambridge, pp.1-10.

Inizan, M.L., Reduron-Ballinger, M., Roche, H., Tixier, J., 1999. Technology and Terminology of Knapped Stone. Cercle de Recherches et d'Etudes Préhistoriques. pp. 189.

Jia L. P., Gai P., You Y. Z., 1972. The report of excavation at Shiyu Site in Shanxi Province .ActaArchaeological Sinica1,39-58.

Jia L.P., 1955.The report of Dincun Homo fossil and lithic artifacts in Xiangfen district, Shanxi Province. Chinese Science Bulletin1, 46-51.

Jia L.P.,1956. The recovery of Chinese handaxes.Chinese Science Bulletin 12, 39-41. Julien, M., 1992 - Du fossile directeur à la chaînes opératoires. In : Garanger (J.), ed., La Préhistoire dans le monde. Paris 
Kleindienst M R., 1961. Variability within the Late Acheulian assemblage in eastern Africa. The South African Archaeological Bulletin 16, 35-52.

Kukla, G., An, Z., 1989. Loess stratigraphy in central China.Palaeogeography, Palaeoclimatology, Palaeoecology 72, 203-225.

Kuman, K., Li, C., Li, H., 2014. Large cutting tools in the Danjiangkou Reservoir Region, central China. Journal of Human Evolution 76, 129-153.

Lepre, C.J., Roche, H., Kent, D.V., Harmand, S., Quinn, R.L., Brugal, J.P., Texier, P.J., Lenoble, A., Feibel, C.S., 2011. An earlier origin for the Acheulian.Nature477, $82-85$.

Li, H., Li, C. R., Kuman, K., Cheng, J., Yao, H. T., Li, Z. ,2014. The Middle Pleistocene handaxe site of Shuangshu in the Danjiangkou Reservoir Region, central China. Journal of Archaeological Science 52, 391-409.

Li L.,1992. A flint knapping experiment of the anvil-chipping techniques and hard hammer percussion technique.Archaeology of Southern Ethic Groups5, 180-197(in Chinese).

Lin S.L., 1992. The cleavers in China.ActaAnthropologicaSinica 11, 193-201 (in Chinese).

Liu Y., 1988. The re-observation of stone artifacts in Dingcun.ActaAnthropologicaSinica 3(4), 306-313 (in Chinese).

Lycett, S.J., Bae, C.J., 2010. The Movius Line controversy: the stage of the debate. World Archaeology 42 (4), 521-544.

Madsen, B. and N. Goren-Inbar, 2004. Acheulian giant core technology and beyond: an archaeological and experimental case study. Eurasian Prehistory2(1), 3-52.

McBrearty, S., Brooks, A.S., 2000. The revolution that wasn't: a new interpretation of the origin of modern human behavior. Journal of Human Evolution 39, 453-563.

McBrearty, S., Tryon, C., 2006.From Acheulean to MiddlePaleolithicin the Kapthurin Formation, Kenya. In:Hovers E, Kuhn S. (eds.)Transitions before the Transition. Springer, pp. 257-277.

Monnier, G.F., 2006. The Lower/Middle Paleolithic Periodization in Western Europe --An Evaluation.CurrentAnthropology 47(5), 709-744. 
Mourre, V. ,2003. Discoïde ou pas discoïde? Réflexions sur la pertinence des critères techniques définissant le débitage discoïde. British Archaeological Reports International Series 1120, 1-18.

Movius, H.L., 1944. Early Man and Pleistocene Stratigraphy in Southern and Eastern Asia. In: Papers of the Peabody Museum of American Archaeology and Ethnology, vol. 19 (3). Harvard University, Cambridge.

Movius, H.L., 1948. The Lower Paleolithic cultures of southern and eastern Asia.Transactions, American Philosophical Society 38, 329-420.

Newcomer,M.H., 1971. Some quantitative experiments in handaxe manufacture. World Archaeology 3, 85-94.

Norton, C.J., Bae, K., Harris, J.W.K., Lee, H., 2006. Middle Pleistocene handaxes fromthe Korean Peninsula. Journal of Human Evolution51, 527-537.

Patole-Edoumba, E.,2009. A typo-technological definition of Tabonianindustries[J]. Bulletin of the Indo-Pacific Prehistory Association 29,21-25.

Pei W.C., 1965. Professor Henri Breuil, pioneer of Chinese Paleolithic archaeology and its progress after him.Miscelanca en Homenaje al Abate Henri Breuil 2, 251-269.

Pei, W.C., Woo, J.K., Chia, L.P., Chow, M.C., Liu, H.T., Wang, C.Y., 1958. Report on the Excavation of Palaeolithic Sites at Tingtsun, Hsiangfenhsien, Shansi Province.

Peresani, M., Soressi, M., 2005. Discoid lithic technology: advances and implications. PaleoAnthropology.

Petraglia, M.D., Shipton, C., 2008. Large cutting tool variation west and east of the Movius Line. Journal of Human Evolution 55, 962-966.

Roche, H., Texier, P., 1995. Evaluation of technical competence of Homo erectus in East Africa during the Middle Pleistocene.Evolution and Ecology of Homo erectus, Royal Netherlands Academy of Arts and Sciences Pithecanthropus Centennial Foundation, Leiden, pp. 153-167.

Shaanxi Provincial Institute of Archaeology, Cultural relics Administrative Committee of Shangluo, Museum of LuonanCounty, 2007. The Paleolithic Open air sites in Luonan Basin, China. Sci. Press, Beijing, 250 pp. 
Sharon, G., 2007. Acheulian Large Flake Industries: Technology, Chronology, and Significance. British Archaeological Reports 1701.

Sharon, G., 2010. Large flake Acheulian. Quaternary International, 223, 226-233.

Shipton, C., Petraglia, M.D., 2010. Inter-continental variation in Acheulean bifaces technology.In: H. L. Dibble and O. Bar-Yosef, ed.Madison: Prehistory Press. pp. 41-67.

Terradas, X., 2003. Discoid flaking method: conception and technological variability. British Archaeological Reports International Series, 1120, 19-32.

Terradillos-Bernal M, Rodríguez-Álvarez X P., 2014.The influence of raw material qualities in the lithic technology of Gran Dolina (Units TD6 and TD10) and Galería (Sierra de Atapuerca, Burgos, Spain): A view from experimental archeology. Comptes Rendus Palevol, 13(6),527-542.

Texier P. J., 1996. L'Acheuléen d'Isenya (Kenya), approche expérimentale des principales chaînes opératoires lithiques. La vie préhistorique, Société Préhistorique Française, 58-63.

Tixier, J., Turq, A., 1999. Kombewa et alii. Paléo 11, 135-143.

Tryon, C.A.,McBrearty, S., 2002.Tephrostratigraphy and the Acheulian to MiddlePaleolithictransition in the Kapthurin formation, Kenya. Journal of Human Evolution 42, 211-235.

Van Peer, P., Fullagar, R., Stokes, S., Bailey, R., Moeyersons, J., Steenhoudt, F., Geerts, A., Vanderbeken, T., De Dapper, M., Geus, F., 2003.The Early to MiddlePaleolithictransition and the emergence of modern human behaviour at site 8-B-11, Sai Island, Sudan. Journal of Human Evolution 45, 187-193.

Wang S. J., Huang P. H., 2001. Stratigraphy and TL Dating of Paleolithic sites in the Luonan Basin, China.ActaAnthropologicaSinica20 (3), 229-237 (in Chinese).

Wang S.J.,2006. Cleavers collected from the open air sites in Luonan Basin, China. ActaAnthropologicaSinica 25, 333-342 (in Chinese).

Wang X.Q., Li Z.Y., Tao F.H., 1987.The prehistory stone manufacturer at Daguduimountain, Shanxi Provience. ActaAnthropologicaSinica 4, 87-94 (inChinese). 
Wang Y. R.,2002. On cultural attributes terms of alluvial taphonomic background at Dingcun Sites. ActaAnthropologicaSinica, 21,158-169 (in Chinese).

Wang Y. R.,2006. The notches and denticulates of Dingcun. In: The oldPaleolithicresearch collection-to commemorateShuidonggou site recovered 80th anniversary. Culture Relic Press, pp. 293-301.

Wang Y.R.,2004. Block on block technique and the flaking method. In: The 80th anniversary for An Zhimin. Chinese University of Hong Kong archaeological research center,22-29.

Wang, S., 2005. Perspectives on Hominid Behaviour and Settlement Patterns, a Study of the Lower Palaeolithic sites in the Luonan Basin, China. British Archaeological Reports International Series 1406. Archaeopress, Oxford.

Wu W.X., Liu T.S., 2002. Study on the loess-paleosol sequence of the Dingcun Paleolithic sites. Seismology and Geology 24, 241-248.

Yang S X, Huang W W, Hou Y M, et al., 2014. Is the Dingcun lithic assembly a “chopper-chopping tool industry", or "Late Acheulian"? Quaternary International 321, 3-11.

Yang S X, Zhang Y X, Zhu T Q, et al.,2015.Provenancing hornfels in the Dingcun industry: The exploitation of the vicinity source. Quaternary International, http://dx.doi.org/10.1016/j.quaint.2014.11.017.

Zhang S. S.,1993. A study on the stone artifacts from 54:100 site in Dingcunregion.ActaAnthropologicaSinica, 12,195-213 (in Chinese).

Zhang S. S., 1994. A study on the stone artifacts from 54:90 site in Dingcunregion. .ActaAnthropologicaSinica13,209-222(in Chinese).

\section{Figure and table captions:}

Fig. 1 Location of the Dingcun site and Fenwei Graben: a.Dingcun and other Acheulean LCTs sites groups; b, Geographic map of Fenwei Graben; c. Dingcunlocalities (After Pei et al,1958)

Fig. 2 Maximum length (L) of stone artifacts from different localities of Dingcun

Fig. 3 Physical condition of the artifacts 
Fig. 4 Examples of large unmodified flakes from Dingcun

Fig. 5 Façonnage (shaping) scheme of the Acheulean large cutting tools (LCT) of Dingcun

Fig. 6 Cleaver flake from Chirki core of Indian Acheulean (after Corvinus, 1983)

Fig. 7 Schemes of small-medium cores reduction of Dingcun

Fig. 8 Illustrations of centripetal bifacial cores of Dingcun

Fig. 9 Maximum length (L) and width of flakes of Dingcun

Fig. 10 Drawing of light duty tools in Dingcun

Fig. 11 Knapping experiment

Fig. 12 Maximumlength (L) and width of flakes form the hard hammer percussion experiment

Fig. 13 Samples of the Hard hammer percussion flakes (from experiment)

Fig. 14 Comparison of platform angles (angle de chasse) of flakes from archaeological assemblage and the two experiments

Table 1 Tooltypology of the studied artifacts 
Figure 1
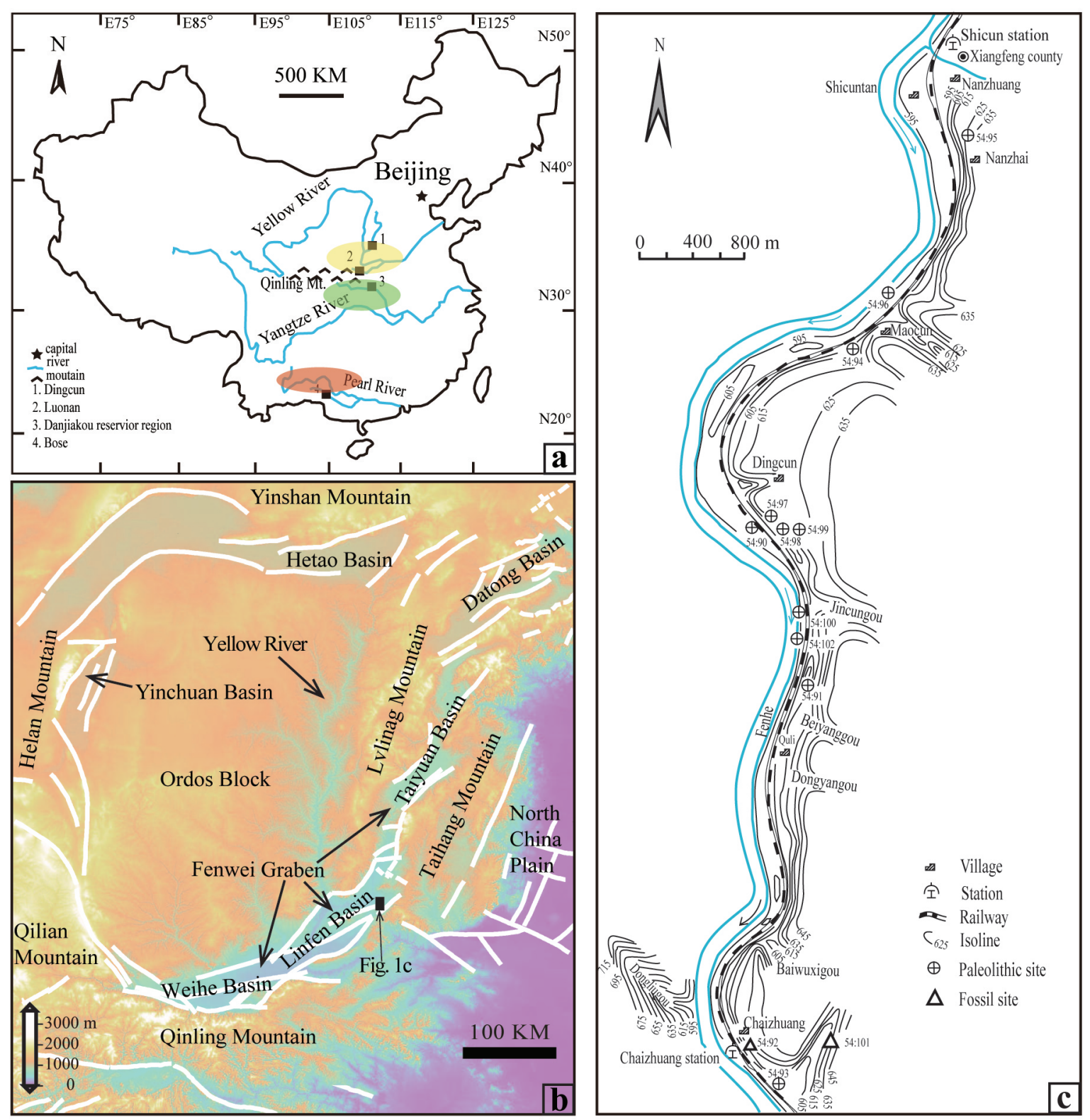
Figure 2

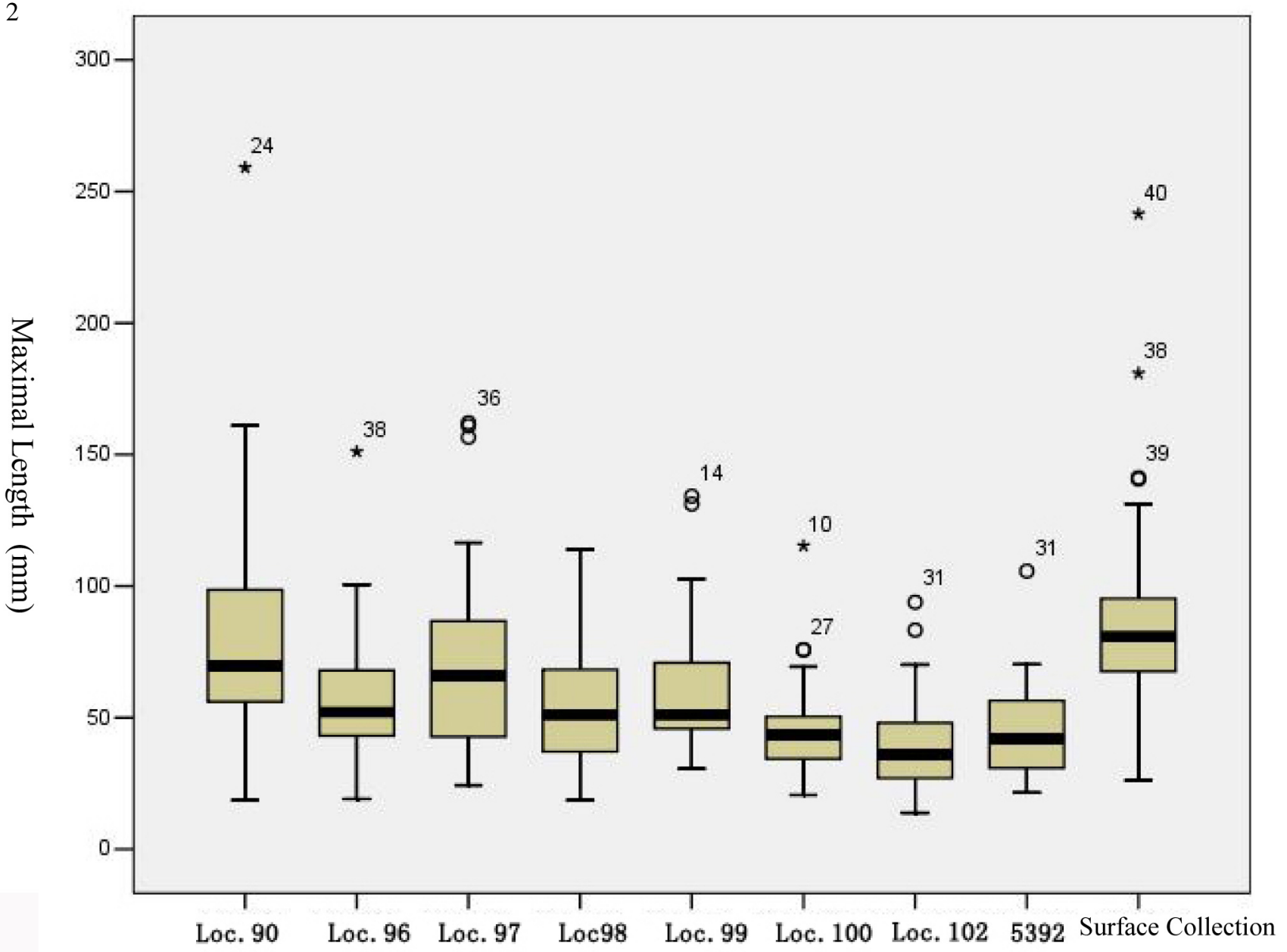




\section{Figure 3}

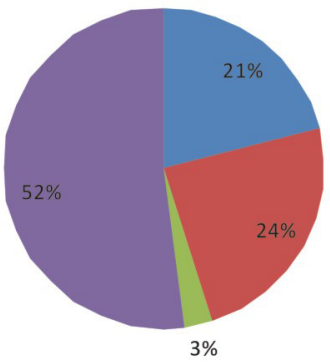

abraded

- Fresh

- Heavily abraded

- Slightly abraded 
Figure 4

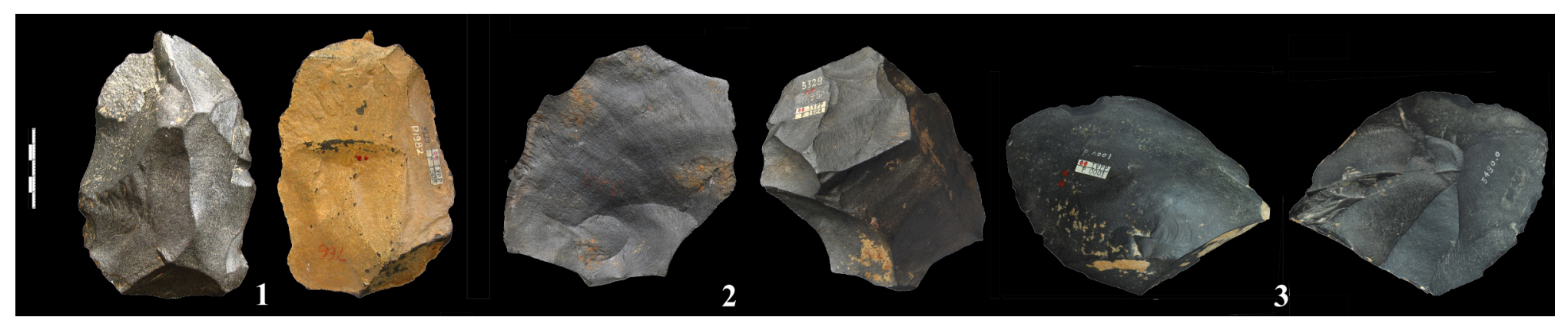




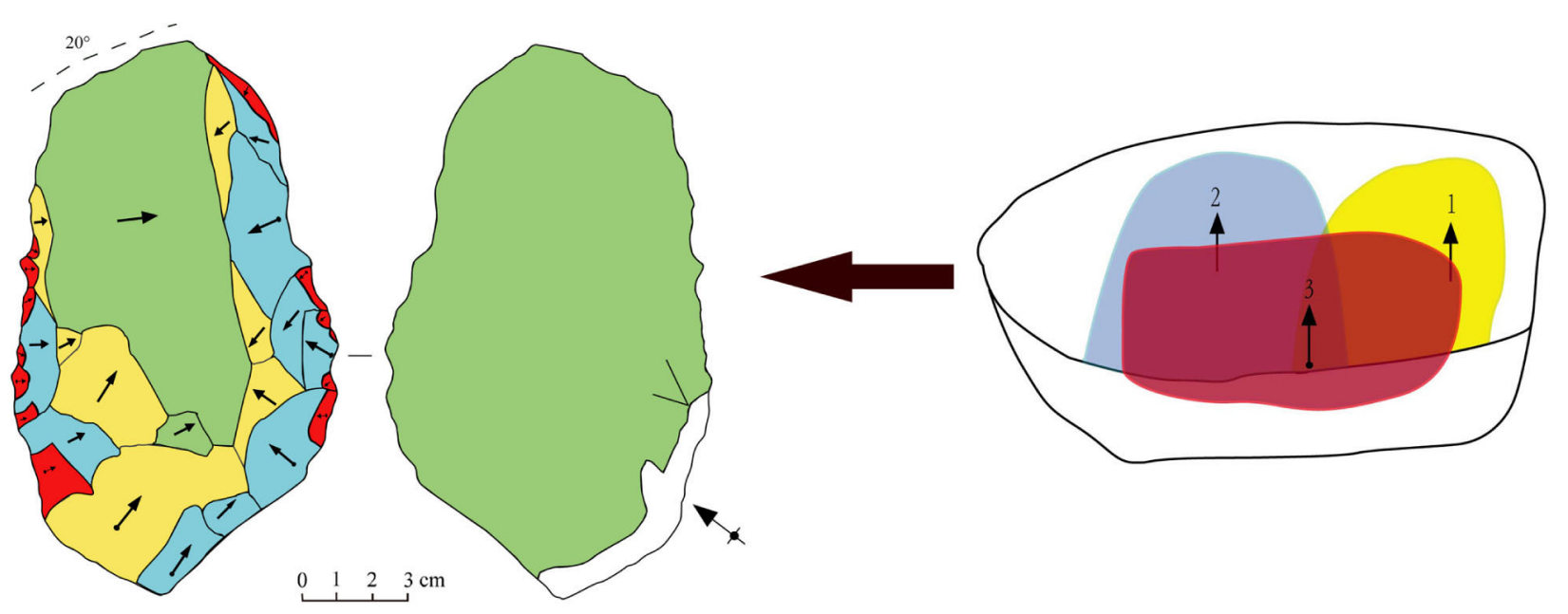

Figure 5

a

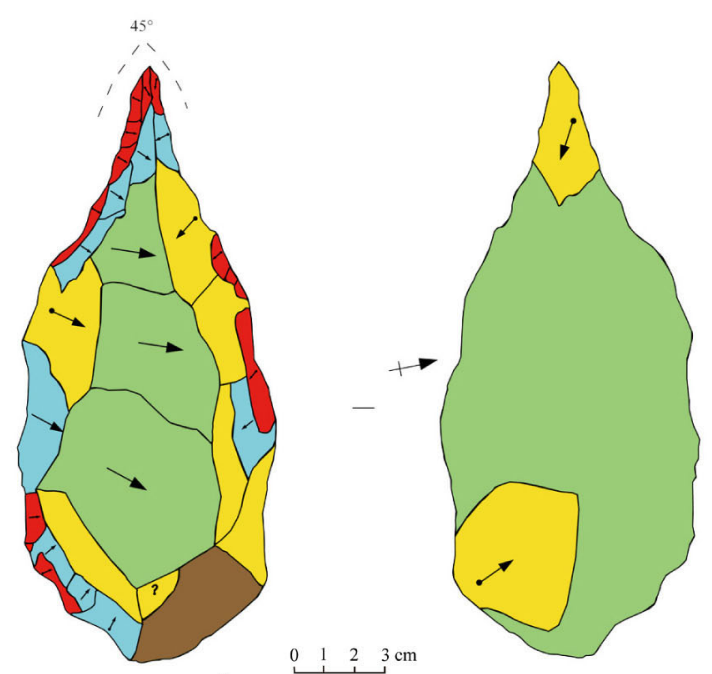

b

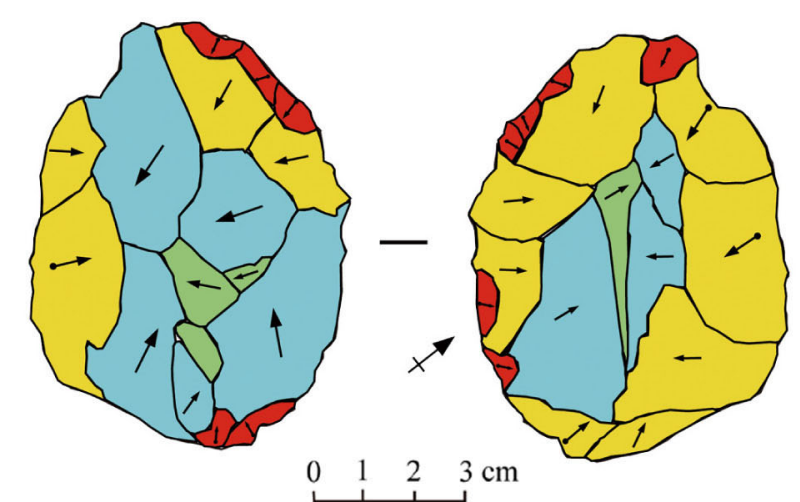

c
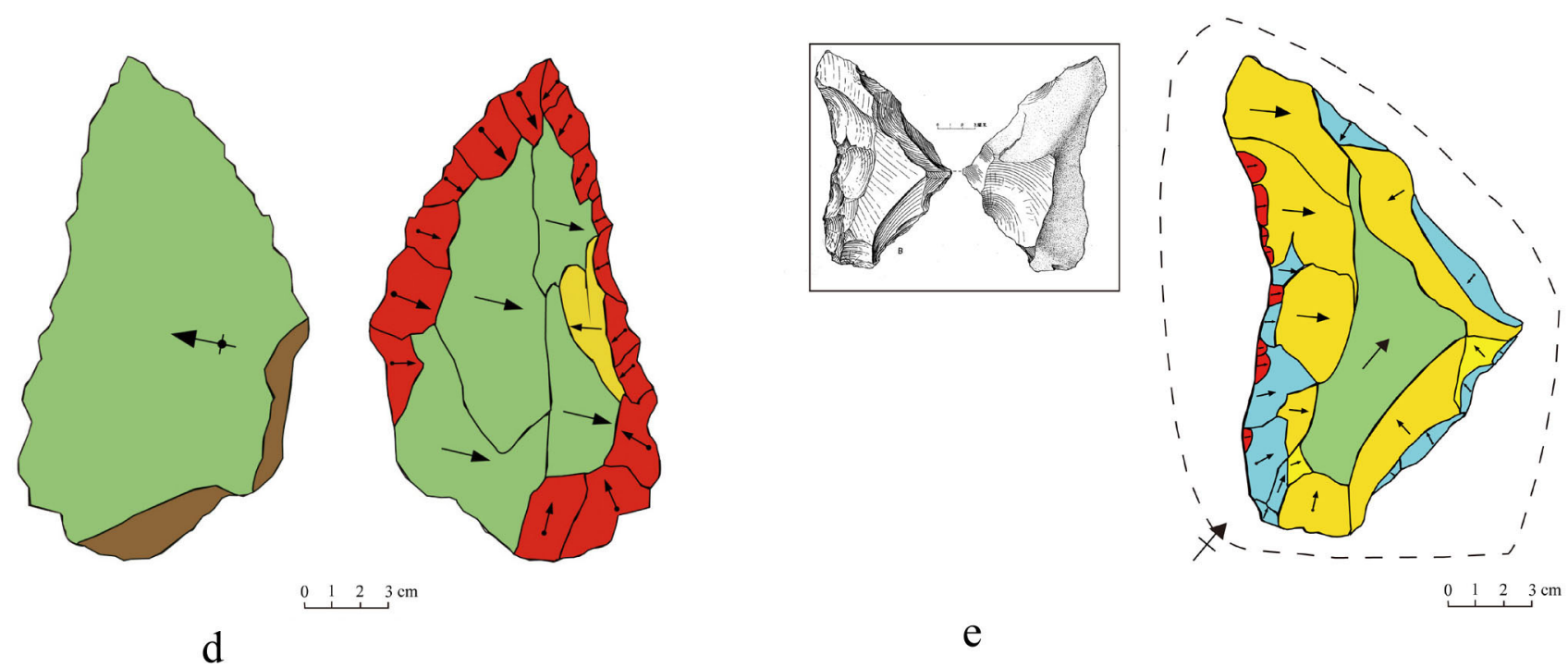

e

$0 \quad 1 \quad 2 \quad 3 \mathrm{~cm}$

Natural facet

The facets on the blank

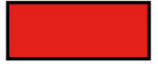

The last retouch stage

The first retouch stage

4 The direction of debitage with a butt
The second the retouch stage

Retouch direction(with the negative bulb)

$\uparrow \begin{aligned} & \text { Retouch direction (without } \\ & \text { the negative bulb) }\end{aligned}$

4 The direction of debitage f without a butt 
Figure 6

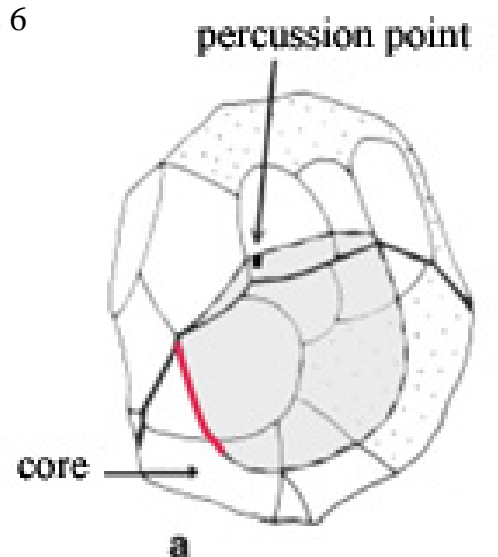

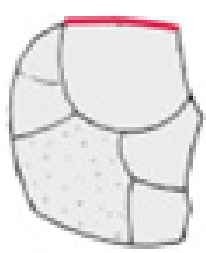

b

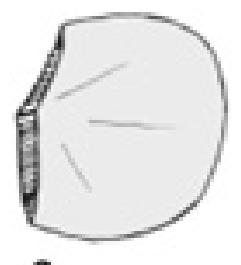

C

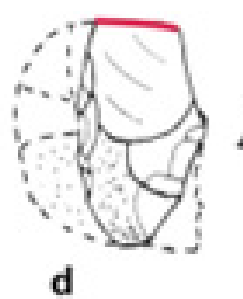

0 
Figure 7

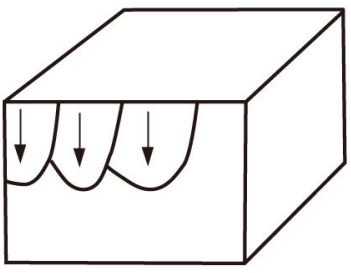

A

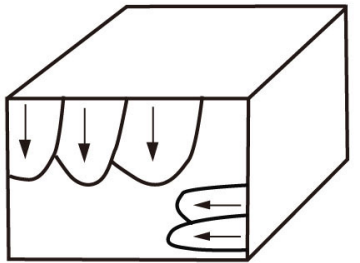

C

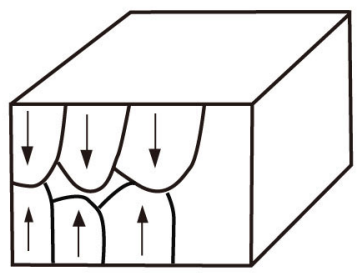

B

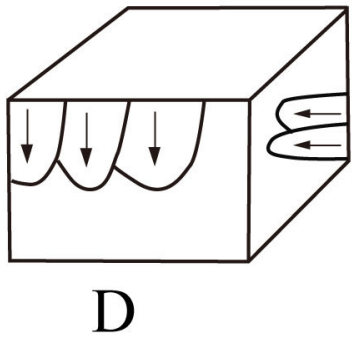

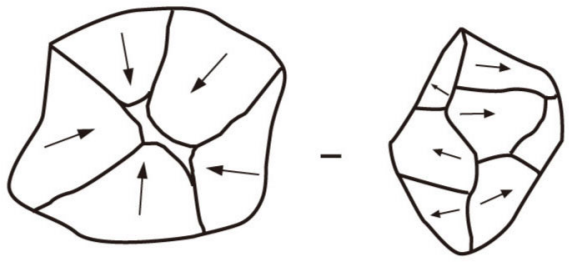

E 
Figure 8
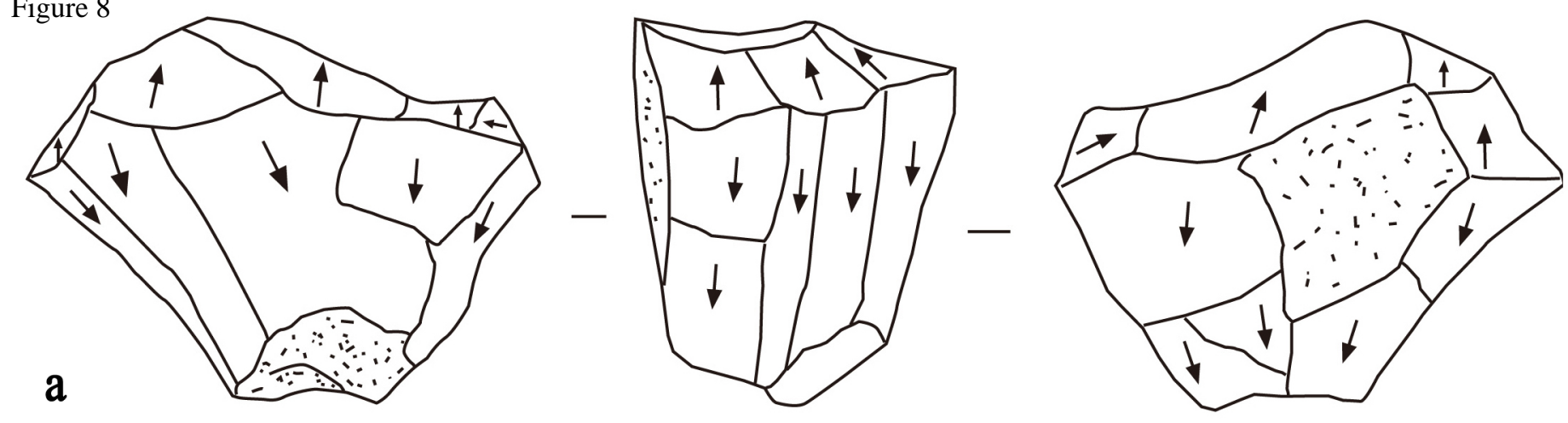

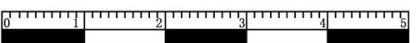

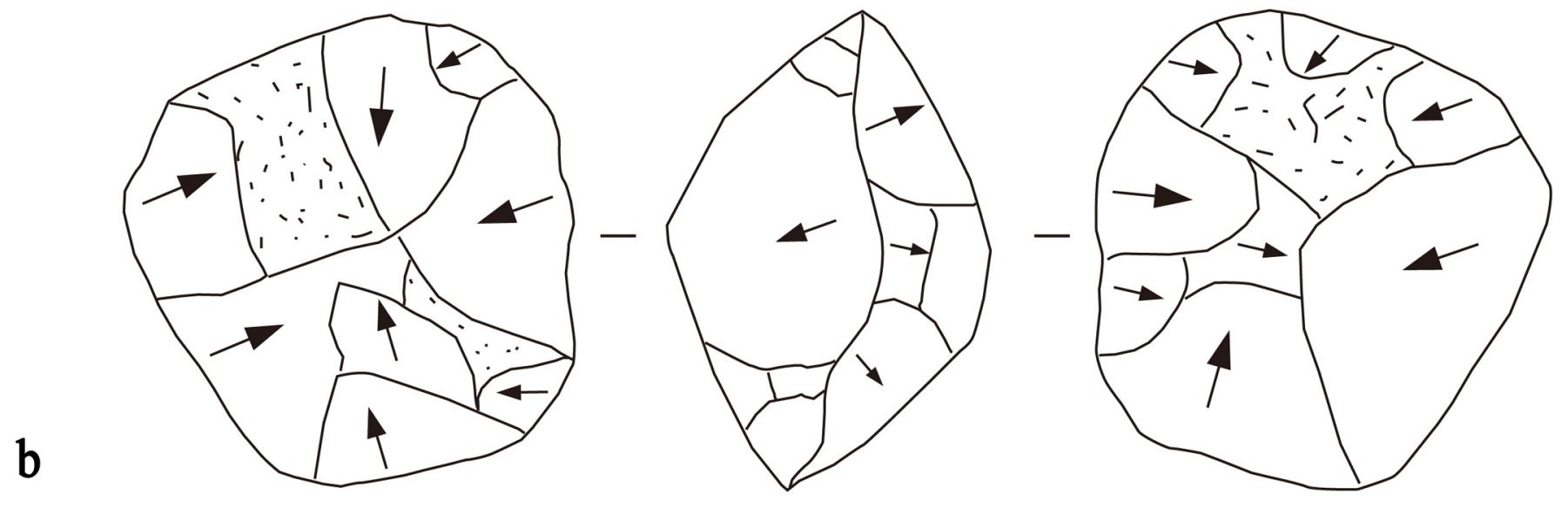


Figure 9

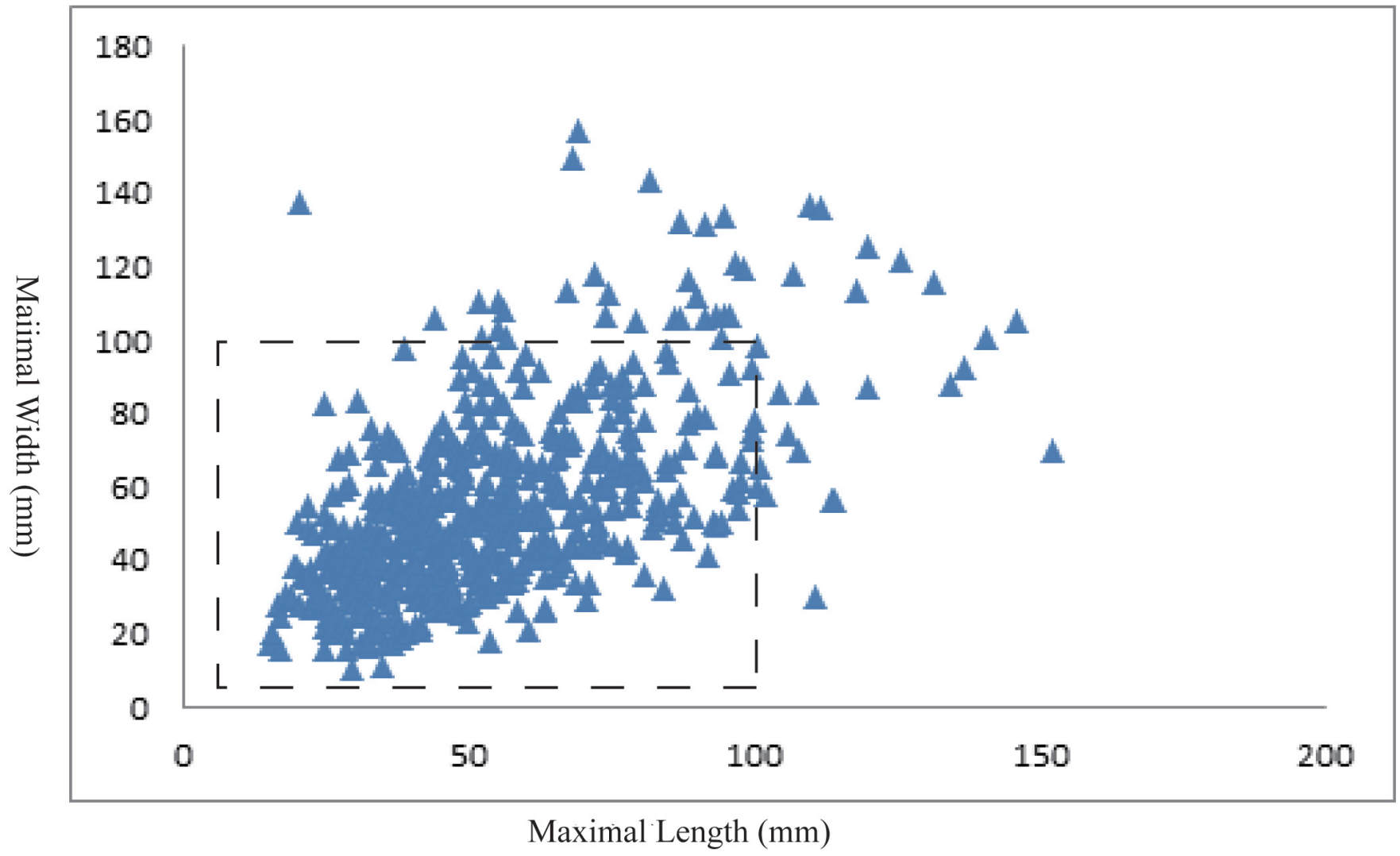


Figure 10
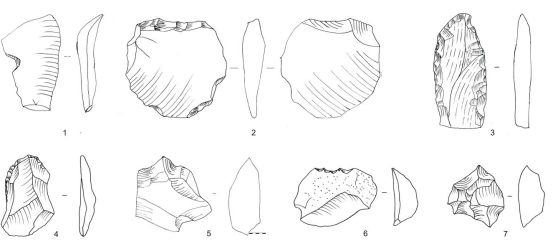

20.0.0 0.0 . 0.0

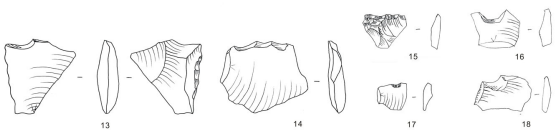


Figure 11

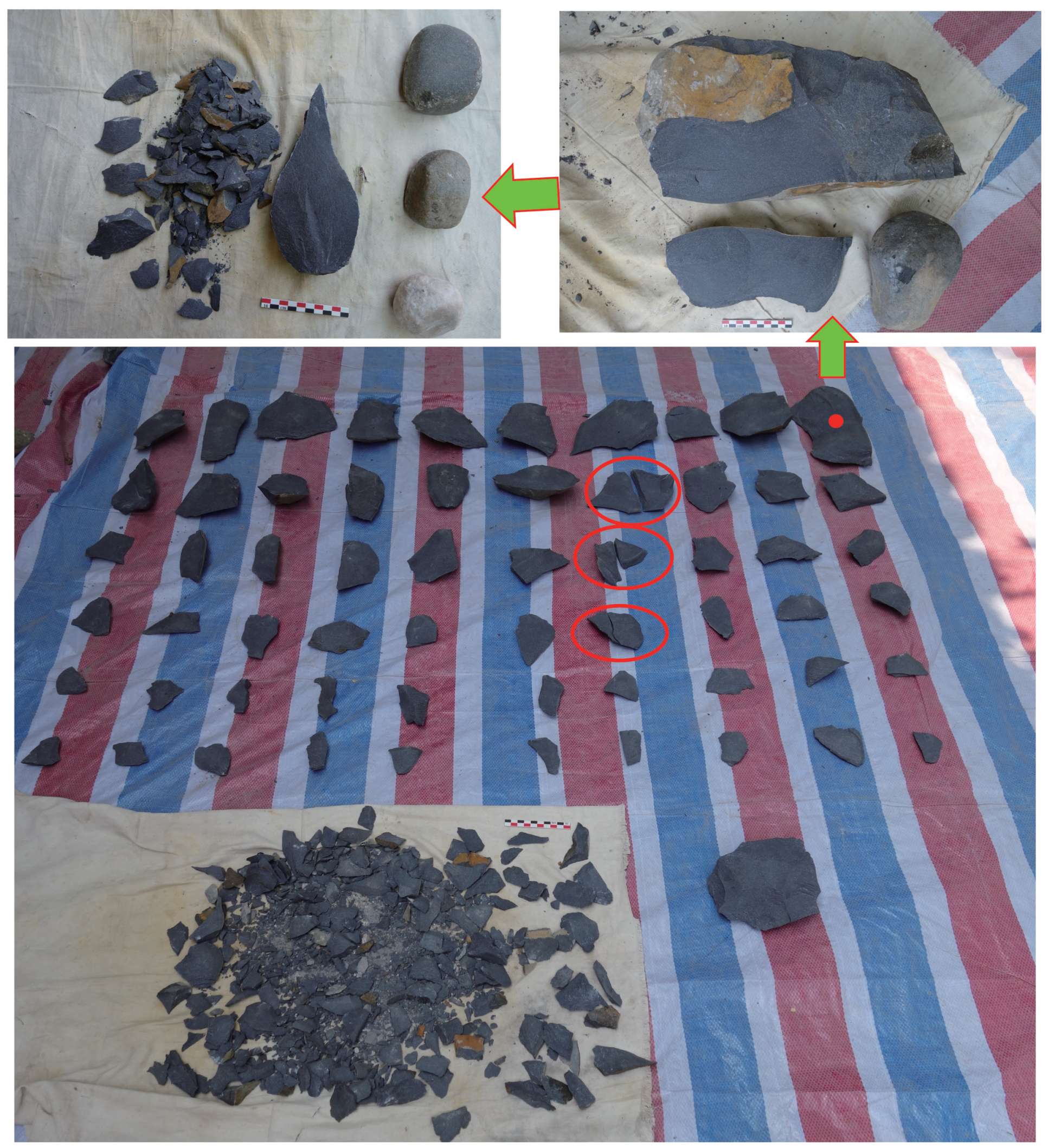


Figure 12

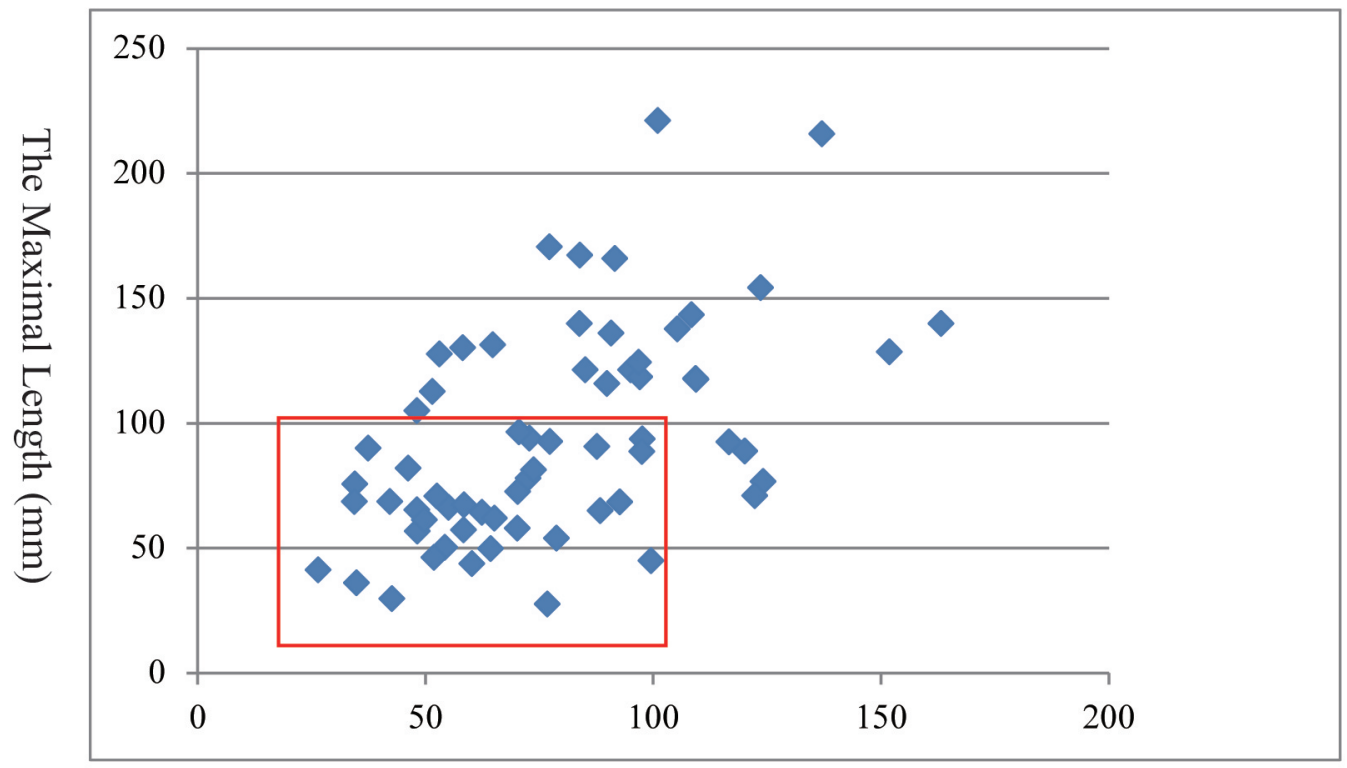

The Maximal Breadth (mm) 

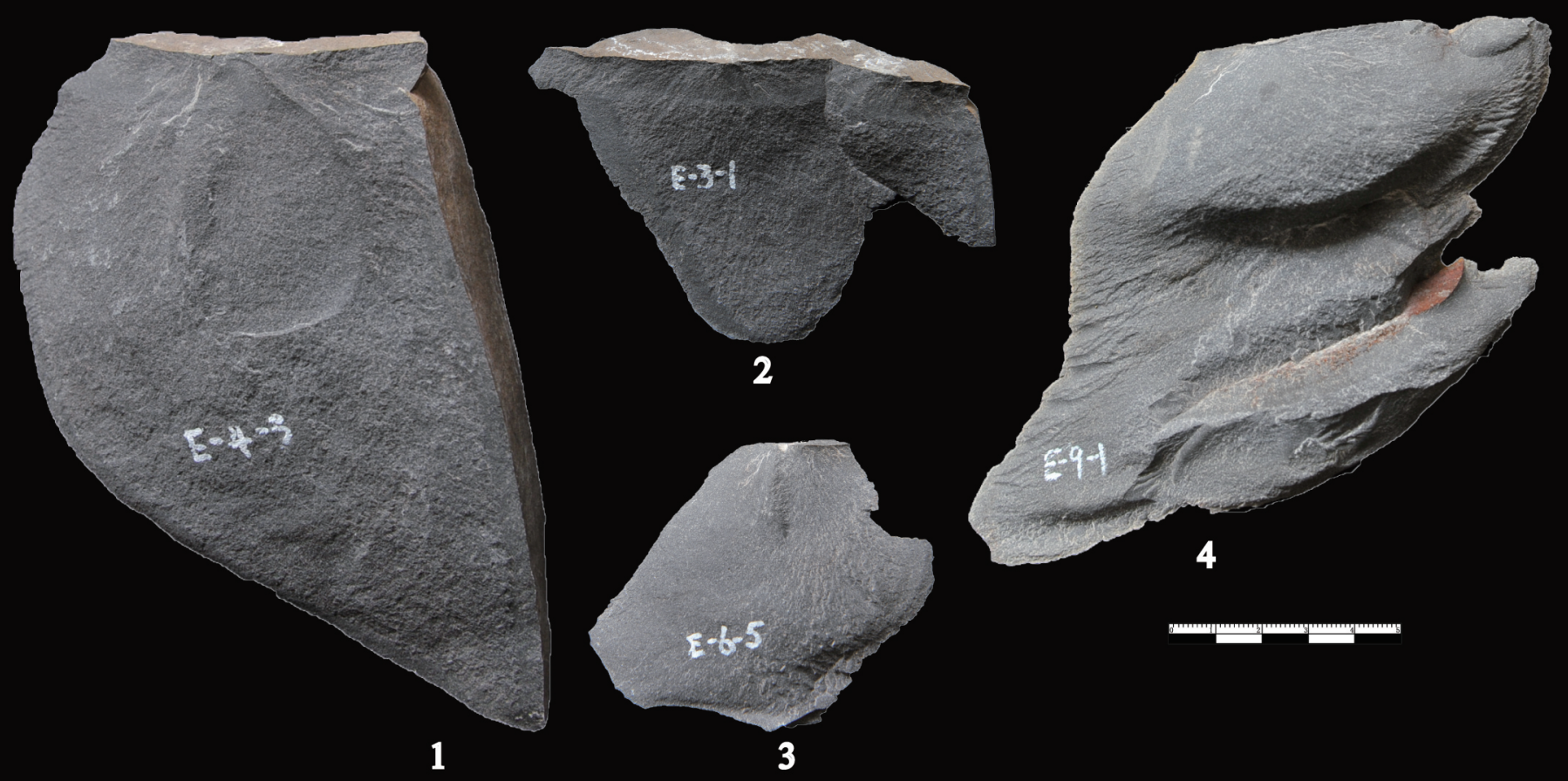


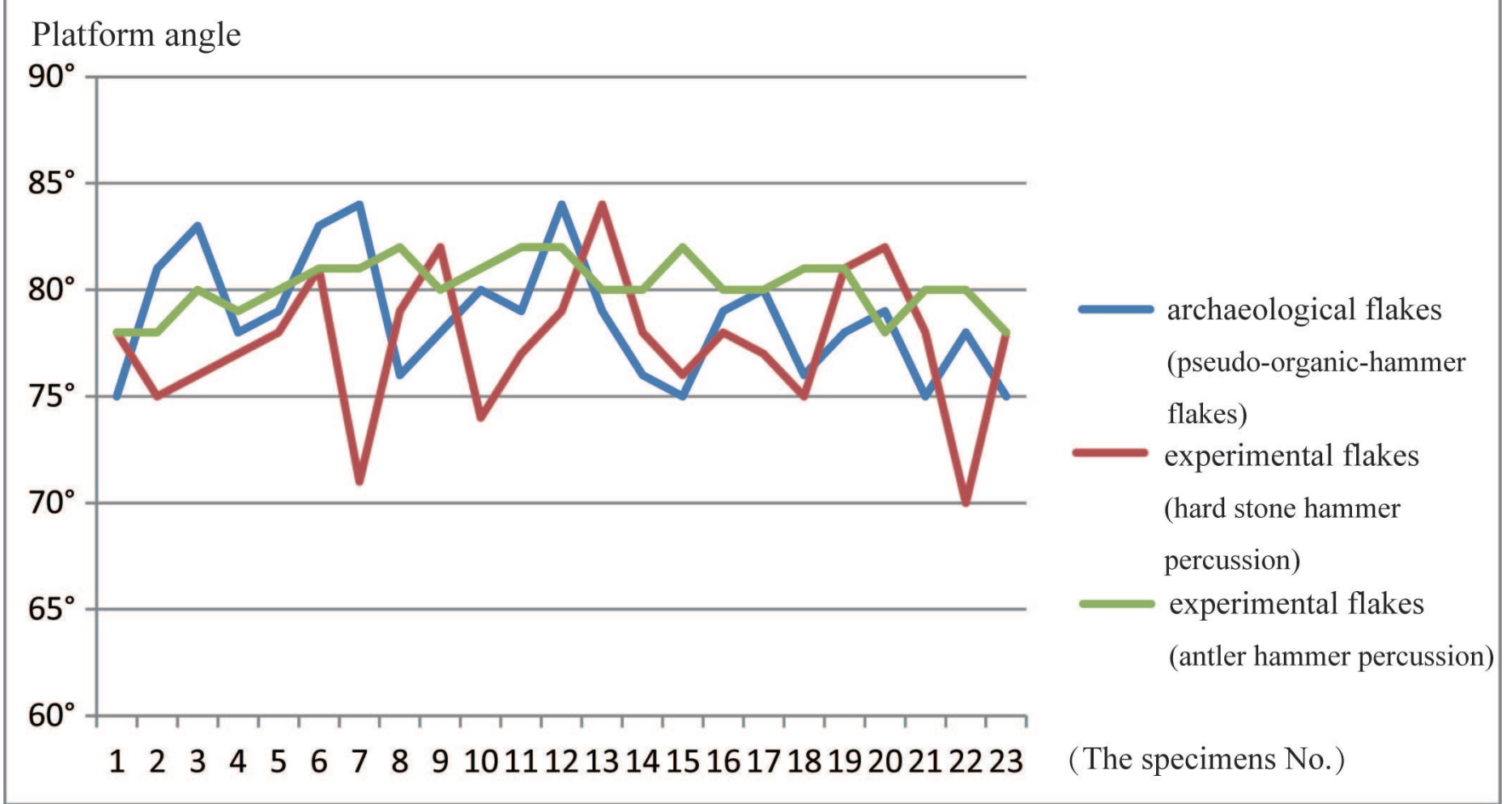


Table 1 Tools typology of the studied artifacts

\begin{tabular}{|c|c|c|c|}
\hline & Typology & Number & $\%$ of tools \\
\hline Large cutting & Handaxe & 10 & $4 \%$ \\
\hline \multirow[t]{4}{*}{ tools (on large flakes) } & Cleaver & 18 & $7.2 \%$ \\
\hline & Pick & 11 & $4.4 \%$ \\
\hline & Massive scraper & 17 & $6.9 \%$ \\
\hline & Massive denticulate & 10 & $4 \%$ \\
\hline Light-duty & Borer & 26 & $10.4 \%$ \\
\hline \multirow[t]{4}{*}{ tools } & Scraper & 63 & $25.4 \%$ \\
\hline & Notch & 34 & $13.7 \%$ \\
\hline & Denticulate & 20 & $8.1 \%$ \\
\hline & Unidentified & 20 & $8.1 \%$ \\
\hline \multirow[t]{2}{*}{ Others } & Spheroid & 13 & $5.2 \%$ \\
\hline & Chopper & 6 & $2.4 \%$ \\
\hline TOTAL & & 248 & $100 \%$ \\
\hline
\end{tabular}

